\title{
Construction machines requirement for the building site
}

\author{
Sergei Sinenko ${ }^{1}$, Boris Zhadanovsky ${ }^{1}$, Vyacheslav Obodnikov ${ }^{1, *}$ \\ ${ }^{1}$ Moscow State University of Civil Engineering, Institute of Construction and Architecture, 129337, \\ Moscow, Russia
}

\begin{abstract}
Economic indicators of construction production are directly related to the choice of the optimal number of machines. The lack of machines for the production of construction and installation works leads to the impossibility of their implementation in the directive period. The pace of construction and installation work and labor productivity depend, to a large extent, on the degree of provision of construction facilities with machines (level of labor mechanization). The article considers the calculations of the need for construction machines for the building site, trust and the ministry. When determining the need for machines for construction sites, it is necessary to take into account ensuring the execution of works in the planned timeframe, increasing the level of complex mechanization, increasing labor productivity and reducing manual work, improving the use of the machine park and their operation. The article presents a consistent set of formulas that must be used when choosing construction machines and determining their number.
\end{abstract}

\section{Introduction}

Lack or excess of machines for the production of construction and installation works (construction and installation works) in construction organizations significantly affects the economic performance of their operation. The pace and quality of construction and installation work, labor productivity largely depend both on the technical level of mechanization tools and on the degree of provision of construction objects with machines (level of labor mechanization).

In determining the need for machines for construction should be considered:

- Ensuring the implementation of work on the objects in accordance with the planned deadlines;

- increasing the level of complex mechanization for construction and installation works;

- increasing labor productivity and reducing the share of manual labor;

- the use of progressive work methods;

- improving the use of the existing engineer fleet;

- ensuring the required rate of the engineer fleet renewal.

\footnotetext{
* Corresponding author: st.obodnikov@gmail.com
} 
The calculation of the need and supply of machines to building organizations should be carried out taking into account the implementation of the entire complex of organizational, technological and operational measures aimed at the constant increase in the efficiency of using the fleet of vehicles [2].

The need to calculate the demand for building vehicles arises at the following levels of planning for the production of construction in determining:

- the need for cars in the development of projects of production of works for the construction of a particular object;

- the need for machines for the program of construction and installation work by a separate construction organization (trust, mechanization management);

- the needs and justification of applications for the supply of machinery to construction agencies or in general in the construction industry.

The method of determining the need for machines for these planning levels is based on the same approach and differs in the level of detail and the amount of input data. In the first case, the source of obtaining the initial data for performing the calculations is the organizational and technological documentation, and in other cases, the averaged over the objects (organizations) are the presented statistical data for the base period (year).

The formation of the construction machinery park should be carried out starting from the process of selecting the means of mechanization in drawing up the work production plan for the building project and further along the hierarchical management structure when planning the development of the park of vehicles at the level of trust (management) of mechanization, the ministry (department) [1].

Determination of the need for machines in the construction industry must also begin at the lowest level (building site) and finally be formed at the highest level of management (the building ministry).

Determining the need for cars at different levels of park formation has its own characteristics both in the methodological approach and in the specific expression, i.e. the need for a unit of work (pcs., $\mathrm{m}^{3}, \mathrm{~m}^{2}$, etc.), for 1 million rubles' construction and installation works (CIW). This takes into account the specificity of the fleet's functioning and purpose (the fleet for the building site, the fleet of the trust or the fleet of the ministry).

As already noted above, the methodical approach in determining the need for the building site, the trust (management) of mechanization and the ministry (department) has differences in defining the initial data, in the formation of basic information.

In determining the need for construction vehicles for an object (by object, we mean separately erected buildings and structures, for example, a dwelling-house, a factory), both specific operating conditions expressed in a variety of soil background, number of storeys, size of cargo, and real conditions associated with this object physical volumes of work with the distribution of the structure (trenches, pits, excavations, etc.). In addition, the time of use of the machine at the building site can vary from several days to several months. After performing a certain amount of work, the need for a car disappears, and it can be used already at another building site, in other operating conditions.

If for machines used with one type of work equipment, as a rule, the operating conditions at various facilities cannot differ in a large number of technological factors, for universal construction machines having several types of replaceable work equipment, the number of technological factors affecting its performance use, expressed in the result of development during the stay at the building site, can be much more [2].

Specifically, this can be shown by the example of a single single-bucket universal excavator. At the building site, the following earthworks should be performed: a vertical layout of the surface should be developed, a soil should be developed in a pit and several trenches, loosened a row of lenses of solid ground, the sinuses should be filled. Moreover, the implementation of these works can only be carried out consistently, and it is 
uneconomical for loosening inclusions to attract additional equipment, such as a bulldozerripper. Hence the need for the use of the following interchangeable working equipment: a front shovel, a back hoe digger, a hydraulic hammer, a clamshell. An excavator can be used with all these types of equipment. This must be taken into account when determining the production of an excavator at this building site. In this case, it is necessary to take into account not only the indicator of the operational output of the machine in physical terms, but also the use of the machine over time.

When determining the need for an object, it is necessary to select machines based on the area of their rational use [4]. One of the significant differences in determining the need or volume is to determine the real output of the machines, in relation to a specific object.

The optimal choice of a particular type of machine in comparison with other types can be justified by the areas of rational use of these machines by the method of finding equations of equal cost.

The calculation of the need for construction vehicles for a trust is advisable to perform for a year. Only if there is accurate data on the amount and structure of work for a longer period (2-3 years), the calculation can be made for the same perspective with subsequent annual refinement of the need based on specific plan targets, taking into account the structure of work methods, such as, for example, for earthworks works on the table 1.

Table 1. Technological methods of work execution.

\begin{tabular}{|c|l|c|c|}
\hline \multirow{2}{*}{$\begin{array}{c}\text { № } \\
\text { s.n. }\end{array}$} & \multicolumn{1}{|c|}{ Technological methods of work execution } & \multicolumn{2}{|c|}{ In \% to total volume } \\
\cline { 3 - 4 } & & Factual & Recommended \\
\hline 1 & Tractors with excavating gear & 2,2 & 2 \\
\hline 2 & Single-bucket excavator & 37,6 & 35 \\
\hline 3 & Continuous bucket excavator & 3,3 & 7,9 \\
\hline 4 & Scraper & 9,4 & 13,6 \\
\hline 5 & Bulldozer & 40,4 & 32,2 \\
\hline 6 & Motor-driven grader & 1,3 & 2,6 \\
\hline 7 & Loading shovel & 1,1 & 2,6 \\
\hline 8 & Other ways of mechanization & 4,2 & 5 \\
\hline 9 & By hand & 0,5 & 0,3 \\
\hline
\end{tabular}

The requirement of the trust in the means of mechanization is formed on the basis of requests for machines need for the building sites, and in addition, for performing unscheduled work (reserve) and work in the production base of construction, which can be determined by analogy with the previous period. In accordance with this, the need for machines for a trust must be determined on the basis of the method of optimizing the structure of the fleet or on aggregated indicators, taking into account the analysis of work in the base period (at least 3 years).

The peculiarity of determining the need for construction vehicles for a ministry (department) is that it is determined for the construction industry as a whole without being connected to a specific object according to the norms of need with a certain adjustment depending on the level of construction mechanization for a given period of time. Demand is determined by the annual volume of construction and installation work in monetary terms, however, this does not take into account the specific model of the machine, which is replaced by the average park number, determined by the sum of the main parameters of the machines ( $\mathrm{m}^{3}$-bucket range, $\mathrm{t}$ - carrying capacity, etc.). The norms by which the need is determined are of a directive nature and are established for a period of 3-5 years. When calculating the norms of demand for construction machines, construction indicators (specific physical volumes of work, structure of methods of mechanization and annual output of machines) are determined taking into account the probabilistic nature of their change in the planned period, based on an analysis of these indicators in the base period. These standards take into account the need 
of ministries (departments) in the means of mechanization, taking into account the relocations of construction machines from one object to another, time spent in repair, the reserve of machinery for performing unscheduled works, etc.

\section{Methods}

When planning indicators for building, trends in the development of mechanization in the planned period are taken into account, during which standards will be in force. From the above, it follows that the degree of accuracy in determining the need for construction machines with increasing hierarchical level of the organization for which it is performed decreases while the complexity of the problem being solved increases.

The determination of the need for construction vehicles is performed in the following sequence: the volumes of work to be performed are identified; the structure of the means of mechanization is determined; calculated operating hourly productivity of machines; calculates the required number of machines to perform the specified amount of work [1].

The calculation of the quantity (need) of construction machines $\mathrm{N}$ is performed according to the formula:

$$
N=\frac{Q}{b_{e c h} \cdot T_{b}},
$$

where $Q$ - the amount of work of this type in natural terms; $b_{\text {ech }}$ - operational productivity of the machine on the execution of this type of work; $T_{b}$ - the duration of the machine in this type of work.

The duration of the machine in this type of work is determined by the formula (10):

$$
T_{b}=\frac{\left(T_{d b}-d_{n B}\right)}{\frac{1}{t_{\mathrm{cm}} \cdot k_{\mathrm{cM}}+D T_{\mathrm{p}}}}
$$

where $T_{d b}$ is the specified duration of the work of the machines, established from the planned schedule, days; $t_{c m}$ - the average duration of the shift, hours; $k_{c m}$ - the average shift factor of the machine work; $d_{n B}$ is the average duration of the machine relocations, days; $D T_{p}$ - the duration of the machine in the maintenance and repair, days/machine hour.

The duration of the machines's stay in maintenance and repair is determined in accordance with the "Recommendations ..." [3]

$$
D T_{p}=\left(\left(\frac{T_{\mathrm{p}}}{t_{01}}-\frac{T p}{t_{02}}\right) \cdot d_{01}+\left(\frac{T_{\mathrm{p}}}{t_{02}}-\frac{T_{p}}{t_{r e c}}\right) \cdot d_{02}+\left(\frac{T_{\mathrm{p}}}{t_{\text {rec }}}-1\right) \cdot d_{t p}\right) \cdot \frac{K_{h}}{t_{r e c}}
$$

where $T_{p}$ is the average resource before the first major repairs, machine hour; $\mathrm{t}_{01}, \mathrm{t}_{02}, \mathrm{t}_{\text {rec }}$ - the frequency of technical maintenance (TM) and current repairs (CR), motorcycle hours; $\mathrm{d}_{01}$; $\mathrm{d}_{02} ; \mathrm{d}_{\mathrm{tp}}$-duration of stay of the car in TM and CR, days; $\mathrm{K}_{\mathrm{h}}$ - the conversion rate of motohours to mash-h.

The specified duration of the machine in accordance with the calendar plan is determined by the formula:

$$
T_{d b}=\left(T_{d}-D_{b}\right) \cdot\left(1-\frac{D_{1}}{T_{d}}\right)
$$

where $T_{d}$ - the planned construction period of the building site (calendar), days; $\mathrm{D}_{\mathrm{b}}$ is the number of days off; $\mathrm{D}_{1}$ is the number of days with adverse meteorological conditions.

When calculating the need for basic machines of the same size, involved in the implementation of two or more types of work, the calculation is carried out according to the formula: 


$$
N_{0}=\sum_{i=1} N_{i}=\sum \frac{Q_{i}}{b_{e c h, i}} \cdot T_{b i}
$$

where $N_{i}$ is the need for machines on the $i$-th type of work; $Q_{i}$ is the amount of work of the $i$ th species in kind; $T_{b i}$ - the duration of the machine in the t-th type of work; bech,i - hourly operational performance of the machine on the implementation of $i$-th type of work.

By the formulas (1) and (5) the need for leading machines is calculated. The need for auxiliary or non-core machines working in the technological complex is determined depending on the performance of the leading machine $[3,4]$.

The number of auxiliary machines, depending on the leading, if the performance of the machines is expressed in the same units of measurement, is calculated by the formula:

$$
N_{b c}=\frac{N_{0} \cdot b_{e o}}{b_{e v}}
$$

$N_{0}$ - the number (need) of leading construction machines; $b_{e o}, b_{e v}$ - hourly operational productivity, respectively leading and auxiliary machines.

\section{Results}

The productivity of the leading and auxiliary machines is expressed in different units of measurement. For example, a concrete pump is an auto concrete mixer, then the need for auxiliary machines is determined by the formulas:

$$
N_{b c}=N_{0} \cdot K_{p r} \cdot \frac{b_{e o}}{b_{e v}}
$$

where $K_{p r}$ - the coefficient of bringing the dimension of the performance of the auxiliary machine to the main;

$$
N_{\mathrm{BC}}=N_{0} \cdot \frac{b_{e o}}{b_{e v, n}}
$$

where $b_{e v, n}$ - hour operating capacity of the auxiliary machine, reduced to the unit of measurement of the productivity of the leading machine.

For example, the algorithm for determining the operational concrete-placing machine operating according to the technological scheme should be considered taking into account the delivery of the concrete mix, the performance of the concrete pump, measured in $\mathrm{m} 3 / \mathrm{h}$.

Concrete-mixing machine is used to ensure the delivery of concrete, the main indicator of which is the capacity of the drum (bunker) $\mathrm{m}^{3}$. The performance of the concrete-mixing machine for the delivery of material from the place of manufacture to the construction site is determined by the formula:

$$
B_{e v}=\frac{V}{t_{r}+t_{p}+\frac{S}{V_{r e c}}+\frac{S}{V_{p}}+t_{m}}
$$

$V$ - volume of the concrete-mixing machine, $\mathrm{m}^{3} ; t_{r}$, $t_{p}$-time of unloading and loading of concrete, hours; $S$-distance from the object to the place of unloading, $\mathrm{km} ; V_{\text {rec }}, V_{p}$ - the speed of movement of the concrete-mixing machine in the loaded and empty states of $\mathrm{km} / \mathrm{h}$; $t_{m}$ - time to maneuver, hours.

\section{Conclusion}

In the development of organizational and technological documentation (construction methodology, work production plan, manufacturing plan), the choice of main machines and 
the determination of their number should be made according to the recommendations and formulas given in the article.

\section{References}

1. M. Ershov, Organizational and technological solutions for the reconstruction of public buildings that are in operation (Monograph, Moscow, 2013)

2. B. Zhadanovskiy, Technology and organization of building production 4 (2014)

3. S. Dmitrusenko, S. Komissarov, The use of elemts of organizational and technological design in the development of production standards, International Scientific Conference (2011)

4. A. Ilyin, E. Romanova, State and prospects of development of production of concrete mixing plants, International Scientific Conference (2011)

5. A. Dubovkina, Managing the process of providing material resources to building sites based on a virtual enterprise (2011)

6. S. Sinenko, I. Miroshnikova, System technology 2, 69-73 (2018)

7. B. Zhadanovskiy, S. Sinenko, I. Miroshnikova, M. Kuzhin, System technology 2, 48-54 (2018)

8. B. Zhadanovskiy, S. Sinenko, I. Miroshnikova, System technology 2, 41-48 (2018)

9. V. Loshakov, S. Sinenko, O. Korol, System technology 2, 19-24 (2018)

10. S. Sinenko, I. Miroshnikova System Technology 2, 14-19 (2018)

11. B. Zhadanovskiy, S. Sinenko, M. Kuzhin, System technology 1, 53-57 (2018)

12. B. Zhadanovskiy, S. Sinenko, M. Kuzhin, Proceedings of Universities. Investment. Construction. Real estate 2, 115-122 (2018)

13. I. Miroshnikova, S. Sinenko, Publication of scientific articles in journal Science and Business: Ways of Development 6, 71-75 (2018)

14. S. Sinenko, E. Danilova, BST 5, 54-55 (2018)

15. B. Zhadanovskiy, S. Sinenko, A. Slavina, BST 4, 43-45 (2018)

16. A. Slavin, S. Sinenko, N. Yoshin, IOP Conference Series: Materials Science and Engineering 21 (2018)

17. S. Sinenko, Ahmetgaliev A., A. Slavin, IOP Conference Series: Materials Science and Engineering 21 (2018)

18. B. Zhadanovskiy, S. Sinenko, E3S Web of Conferences Cep. "High-Rise Construction 2017 (2018)

19. S. Novikov, B. Zhadanovskiy, S. Sinenko, MATEC Web of Conferences, 22nd International Conference on Innovative Manufacturing Engineering and Energy (2018)

20. S. Novikov, B. Zhadanovskiy, S. Sinenko, Guidelines on calculation of the concrete thermal treatment modes, MATEC Web of Conferences (2018)

21. P. Oleynik, B. Zhadanovskiy, S. Sinenko, M. Kuzhin, V. Brodsky, L. Pakhomova, Construction of monolithic structures of buildings and structures, monograph (Moscow, 2018)

22. S. Sinenko, B. Zhadanovskiy, L. Pakhomova, IOP Conf. Series: Materials Science and Engineering 463 (2018) 
23. S. Sinenko, A. Feldman, IOP Conf. Series: Materials Science and Engineering 463 (2018)

24. S. Sinenko, A.B. Zhadanovskiy, S. Moiseeva, IOP Conf. Series: Materials Science and Engineering 463 (2018) 